\title{
Application of Virtual Reality Technique to Civil Engineering
}

\author{
Yaodong Sun, Xi Chen, Zichen Huang, Dexi Tao, Lihong Chen, \\ Changdong Zhou, Li Liu, Qian Zhou \\ National Experimental and Teaching Center for Civil Engineering, Beijing Jiao tong University, \\ Beijing 100044, China.
}

\begin{abstract}
With the development of science and technology, virtual reality (VR) technique has been applied to various fields. In civil engineering, the application of VR technique to field practice and training has still been limited. By summarizing the characteristics of field practice and training, the potential applications of VR technique in civil engineering have been discussed. Taking the virtual laboratory of civil engineering in Beijing Jiaotong University as an example and basing on the experiences of developed VR modules, the advantages and disadvantages of VR techniques have been pointed out in this paper, which could be referred by the similar laboratory in the other universities.
\end{abstract}

Keywords: Civil Engineering, Virtual Reality Technique, Augmented Reality Technique, Virtual Laboratory, Field Practice.

\section{Introduction}

Virtual reality (VR) technique is an integrate computer technology which can give the user an immersive experience. With the development of software and hardware, VR technique also grows rapidly. Creating a virtual scene, VR technique provides the user an audio-visual or even tactile experience, and reacts by users' manipulation to make user an immersive feeling. The features of VR technique could be summarized as 'three Is' which is Immersion, Interaction and Imagination. Moreover, it also can reflect people's subjective initiative [1]. Based on the features above, VR technique has been fully applied in different kinds of fields. For instance, NASA has developed a training system for aviation and satellite preservation, SRI international conducts training about the plane or vehicle navigation via VR techniques[2], in order to reduce the probability of flying or driving accident. VR technique has great influence on fields which emphasize hands-on approach or those that has low error-tolerant rate, like Medical Engineering and Medical Education, especially surgical therapy of which VR techniques provide a multiple and repetitive chance for students to practice their manoeuver.

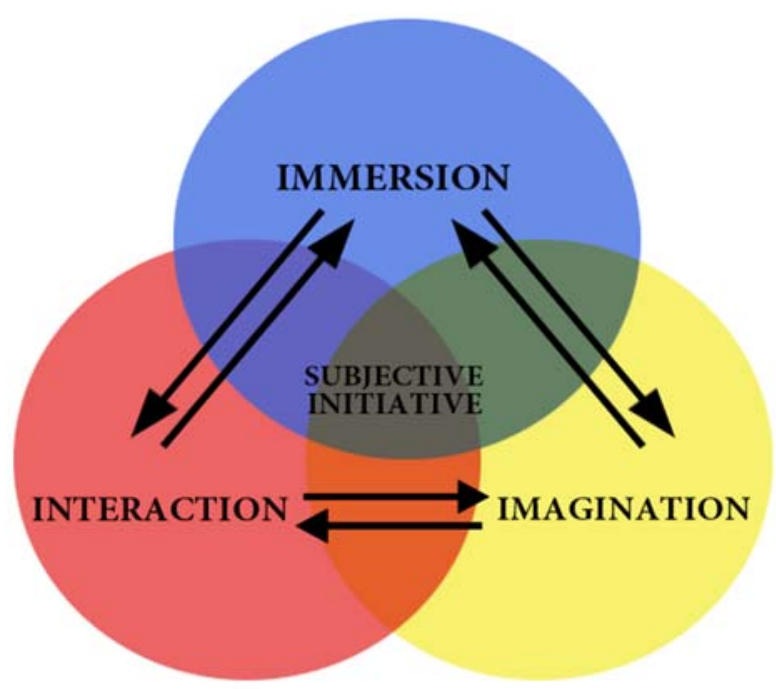

Figure 1. VR Technique Provides 
In traditional civil engineering, people need to use some abstract conceptions to indicate abundant and specific details, like using plan, elevation, profile map and some conventional symbols to denote a building structure, however, which is very inefficiency. Recently, along the advance and development of VR technique, it has gained more utilization in this traditional field. Based on the experience of developed VR modules, point out the advancement and future development prospects, wish it may be referred by the other similar universities.

\section{The Application and Features of VR Technique in Civil Field}

As a rising innovative technology, VR technique has been widely used in every engineering areas and attracts more companies get into the VR market. In recent year, having advance towards civil engineer. VR has deeply changed this field. While the knowledge of civil engineering is abstract that focus on the incorporation of theories and practices, it can be more comprehensive in basic theory, design, construction, etc., by introducing VR technique into civil industry. When it comes to higher education, advantages of VR techniques shine via classroom teaching, experimental introduction and field practice.

\subsection{The Application in Classroom Teaching}

Using VR technique in a flexible way can enhance teaching efficiency and quality with following examples.

\subsubsection{Educational Models}

Elaborately, VR can be used to exhibit virtual models, reconstruct a real project, and transform the text and graphics to scenes which enable students to gain knowledge from it actively. To summarize, it evolved the teaching method from 2D to 3D. Taking the soil mechanics-a foundation course of civil engineering-as example, VR technique and virtual scene enable student shrink into a particle, travel through the pores of soil mess accompany with pore water, which can help student comprehend the different formation of water around the soil particles and the compression and deformation process of soil. Of course, VR techniques have potential in engineering drafting and other courses. It assists students to figure out the difficulties and enrich the teaching method.

\subsubsection{Innovation of Course Design}

Take the bridge foundation design for example, placing students into virtual target structure to make them have a better understanding of the designing intention. In the meantime, it also disintegrate the entire design. For instance, from load calculation and calculation of foundation bearing capacity to determination of foundation dimensions, students can fully understand the design workflow. By means of the interaction function of VR technique, students can easily finish their course design in the virtual scene. Furthermore computer can score students work specifically and give revision suggestion, achieve the aim of intellectualization of VR technique.

\subsection{The Application in Virtual Experiment}

Build a VR laboratory has a profound and practical significance. By far, universities are troubled by the lack of experimental site and space, and the device is old-fashioned or damaged, highly experimental consumption and risking experiment. Provided that apply VR into virtual laboratory, problems above would be eased. Predictably, building virtual-real synthesis laboratory that combines virtual simulation and tangible physics experiment would be the new development direction of civil engineering experiment introduction. Following goals can be achieved by building the virtual simulation. The picture below shows a virtual simulation soil mechanics lab of civil engineering in Beijing Jiaotong University. 


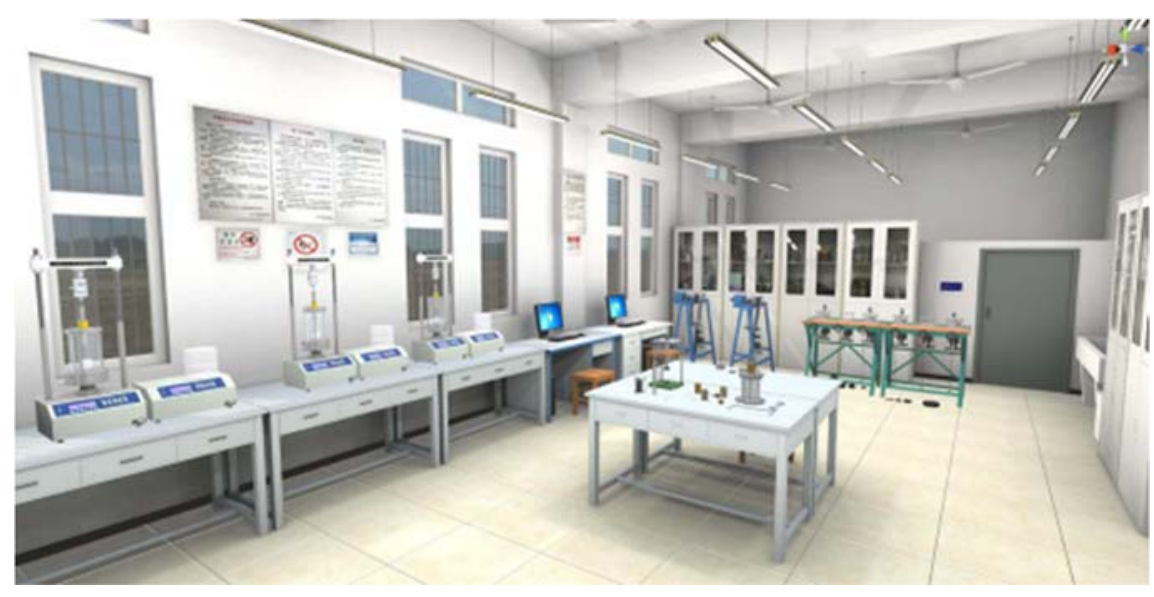

Figure 2. Virtual Simulation Lab of Civil Engineering in Beijing Jiaotong University

\subsubsection{Knowledge Mastering}

Due to the limitation of the condition of the experiments, many physical experiments are hard to process. What's worse, some abstract concepts can't be exhibited by the normal experiment, such as crack initiation in the beam body, which limit students' understanding of knowledge points. However, this problem can be solved by building a virtual laboratory based on VR or AR techniques that provide students study in doors and understanding the key point as well as the experiment process.

\subsubsection{Experimental Skills Improving}

Using virtual experiment modules can improve the operational ability. Some experiments require repetitive training to master certain skills. Besides, some experiments may cause the wear of the facilities and consumption of material which would both raises the cost of the experiment. Students' inexpertness limits their improvement. Thus, the virtual experiment can be the advance test of the physical experiment, which provides repetitive training and then improve students' proficiency of practical operation and raise successful rate of the physical test. It's clear that combining advance virtual experiment and the real physical experiment to improve students' experimental skills is an efficient teaching method.

\subsection{The Application at Field Practice}

It's of great importance for civil engineering to combine theory and practice that's why field practice is indispensable in civil education. However field practice may result in a bad outcome. That is to say the huge amount of students and the few of the instructor lead the field practice to a mere glimpse. The limitation of time nodes reduce the duration that students can just learn a part of process and construction method of the whole phase. The limitation of environment and safety factors restrict students from learning closely about construction situations. The table below shows the comparison between VR practice and fieldwork from which we can tell that applying VR techniques to fieldwork can solve problems above by guaranteeing an observation of entire process and comprehension of each construction links and details [3-6]. Of course, VR practice also can be the antecedence of fieldwork that the combination of both improves practice effect. The picture below shows the tunnel module based on innovational project developed by the students.

Table 1. The Comparison between VR Practice and Fieldwork

\begin{tabular}{|c|c|c|}
\hline Main features & Fieldwork & VR practice \\
\hline Realizability & $\begin{array}{c}\text { The real scene(transport vehicles, } \\
\text { application field) }\end{array}$ & $\begin{array}{c}\text { VR laboratory( computer hardware and VR } \\
\text { helmet) }\end{array}$ \\
\hline Risk & Varying degrees risk & None \\
\hline Cost & High & Low \\
\hline Time and space & Dtationary time and place & Anytime, anywhere \\
\hline Immersion & Weak(one-to-many) & Strong(one-to-one) \\
\hline Enjoyment & Low & High \\
\hline
\end{tabular}




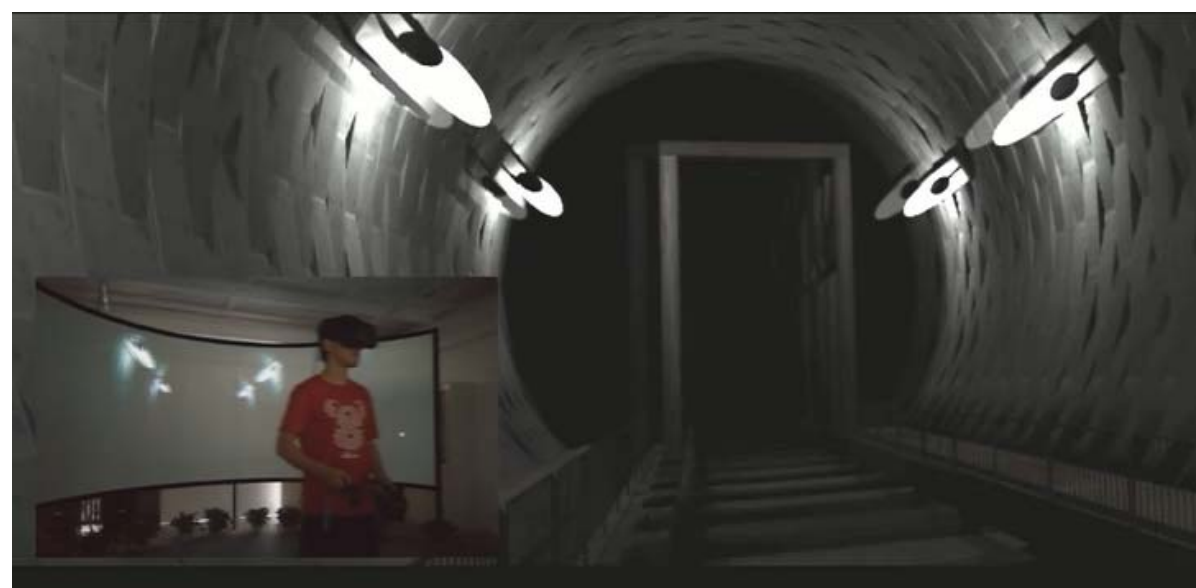

Figure 3. Tunnel Module Based on Innovative Project Developed by the Student.

\subsection{The Advantage and Feature of the VR Technique}

According to the analysis and comparison with form 1 I mentioned above, there are the following advantages and features of the VR technique.

In practical aspect, VR education and VR internship just need a relatively small space to carry out by purchasing computer hardware and software and VR device, in order to give the experiencer a feeling of actually being there. By contrast, the real fieldwork always requires advanced schedule and fixed sites, let alone the transportation. The whole process will drag in lots of people and every link should be closely integrated.

In risk aspect, VR experience is carrying out indoor that avoid the possibility of some accident such as fall and burn, which decrease the risk rate to zero. At the same time, as the former fieldwork curriculum, VR fieldwork experience and safety training indeed decrease danger of the later real field practice.

In cost aspect, space and the computer hardware of VR can be purchased in one shot and enable us to use over and over again. It can avoid the problem of transportation and accommodation, which lower the cost. Besides, VR technique is able to solve the problems of wear and tear of the facilities and materials.

In space and time aspect, field practice always limited by time and sites. Some civil engineering fieldwork site will no longer exist after finishing construction. However, the VR technique is able to conserve the site forever. For one specific site and the period of time, we can only learn about the seasonal working method and contents, which lack the comprehensive process and steps. While VR fieldwork is not restricted by time and space, carrying out in all long for students to absorb the knowledge about all-sides process is possible.

In immersion aspect, field practices always affected by the enormous of students and most of them cannot concentrate in the practices, leading the discount of the effect of the field practice. According to our experience and feedback, the fact that a large group of students have field practice together at the same time teaching by only one teacher result in little concentration which leads only a few students can finish the report with a relatively high quality. In this case, VR internship is a kind of one-to-one method, in which students can treat themselves as dominating part, carrying on the practice initiatively and aiming at something unfamiliar to master.

In enjoyment aspect, field practice brings the sense of freshness to students, which sometimes cause the distraction of specific knowledge. Actually, VR is a technique for computer games whose programing software-Unity $3 \mathrm{D}$ is extensively used in the development of games on the phone and PC platform. Above all, VR technique exposes the feature of the interest, combining education with pleasure and knowledge with fun and enabling students concentrate on knowledge that arrangement in VR scene in advance.

Although VR technique has many merits I mentioned above, VR lab also has the problems, like the limitation of space and the quantity of the VR equipment. Nevertheless, with the rapid development of VR, the mobile VR glasses have already popularize. Students can download the 
software and use online, experiencing the VR module. In this case, children can arrange their schedule better, preparing the following experiment in field practice which can improve students' knowledge systems.

\section{The Meaning of Civil Engineering VR Laboratory}

In order to satisfy the needs of the plan, known as the "Double-First Class", which would internationalize the civil engineering education[7]. It includes the internationalization of teachers, students, scholarship system, administration and management. Especially internationalize the model of instruction. Besides language teaching and curriculum system, internationalization of the model of instruction contains the teaching methods. Nowadays, Chinese teaching and experimental methods are still very monotonous, most of that use blackboard-writing and multimedia teaching. Under this circumstance, it is necessary and efficient to develop and erect VR laboratory to offset the problem of lack of experiment sites and assistants. Utilizing the VR technique, as supplement of traditional education pattern, to expand class instruction, experimental teaching and field practice education is of great importance.

\subsection{Solution for Scarcity of Teaching Resources}

At present, the geographical distribution of Chinese higher education resources is uneven. Some university owns abundant education resources, including numerous laboratories while some universities lack the basic facilities. Although the college in first-tier cities, like Beijing, Shanghai and Guangzhou, has strong financial backing, they are also limited by the narrow space, which results in the dissatisfaction of hundreds of students' needs simultaneously. It challenges us the "DoubleFirst Class" initiative, while constructing VR teaching pattern and lab can figure out this problem appropriately by providing solutions for scarcity of teaching resources.

\subsection{Diversification of Instruction Pattern, Experiment and Field Practice.}

Affected by exam-oriented education chronically, students usually accept the passive one-to-many education, which leads to the distraction of the students when teacher teaching for the whole class without any interactions. In other words, just one teacher cannot give consideration to multitudinous students, which cause the inefficient in class teaching and limit students' innovation. It is essential to introduce VR technique by establishing VR curriculum and experiment which will diversify instruction pattern. With the help of the VR tech, we can change the educational patterns, from teacher-centered passive cramming education to student-centered active absorbing the knowledge and from one-to-all simultaneous learning model to one-to-one demands learning model, developing the new teaching model by combining book, multimedia, VR laboratory and real experiment.

\section{Prospect of VR Application in Civil Engineering}

\subsection{The Creative Effect to Future Education}

Artificial Intelligence, Big Date Analysis and Virtual Reality are regarded as three cutting-edge techniques that influence the direction of future technology. With the help of virtual reality and augmented reality, the education will be more variable which would influence the higher education and learning method in all dimensions.

\subsection{The Leading Effect to Future Technical Development}

VR is an integrated technique that involves computer science, numerical computation, vision and artificial intelligence. As one of the three innovated technologies, it is easy to foresee that its application would deeply impact the traditional education and driving the interactive progress between different kinds of field including civil engineering. 


\subsection{The Tendency of VR Future Development}

Based on research and analysis, I would like to divide VR progress into three developing phases: (1) virtual simulation stage (2) virtual reality or augment reality (3) virtual reality combined with numeric calculation software. Currently, we are in the VR and AR developing stage which users can experience and operate the predefined scenes. However, there are numerous uncertainties in real spot. The combination with refined numerical simulation and virtual reality will bring VR into a new stage and have a deep influence on other fields.

\section{Conclusion}

With the rapid development and progression, VR had has a significant impact on civil engineering. In the higher education of civil engineering, the advantages of VR technique are obvious which indicate by classroom teaching, experimental instruction and field practice. Expanding the patterns of classroom teaching, experimental course and fieldwork by VR technique can release the heavy pressure of teaching resource. What's more, it can change the educational patterns, from teachercentered passive cramming education to student-centered active absorbing education and from oneto-all simultaneous learning model to one-to-one demands learning model. As far as we foreseen, VR and AR techniques will achieve a higher standard by incorporating other frontier technologies and commonly used in other application fields.

\section{Acknowledgments}

Project application of virtual reality technique to civil engineering supported by Beijing Jiaotong University Training Program of Research for Undergraduates.

\section{References}

[1]. Wang Gang the Study and Development of 3D Virtual Simulation System for the Gas Pumping and Condensing Sections of Coking Plant.

[2]. Jiang Xuezhi Li Zhonghua. Present situation of vr researching at home and abroad, 2004, 23(2).

[3]. Jiang Fengxia Sun Yue Li Ruiguang. The Application of Virtual Reality in Education Teaching, 2014, (4).

[4]. Liu Dejian, Liu Xiaolin, Zhang Yan, Lu Aofan, Huang Ronghuai. The Application of Virtual Reality Technology in Education: Potential, Current Situation and Challenges 2016, 22(4).

[5]. Chen Qi Liu Rude. Contemporary Educational Psychology [M]. Beijing Jiao tong University Publisher 1999 98 100;101 104.

[6]. Wang Tongju. The Application and Prospect of the VR and AR Technique in Education, 2017, $3(1)$.

[7]. Chen Xi Internationalization of higher education in civil engineering of Singapore: Measures and Revelation. Higher Construction Engineering Education, 2011, 20(4): 11-15.

[8]. Jiang Xuezhi Li Zhonghua. Present situation of vr researching at home and abroad, 2004, 23(2). 